\title{
Familial glucocorticoid deficiency presenting with hyperpigmentation, gigantism, and motor development delay: a case report
}

\author{
Kanchana Uyangoda ${ }^{1}$, Phirarthana Kamalanathan ${ }^{1}$ and Sachith Mettananda ${ }^{1,2^{*}}$ (D)
}

\begin{abstract}
Background: Familial glucocorticoid deficiency is a rare autosomal recessive disorder characterized by isolated glucocorticoid deficiency. Most patients are diagnosed following episodes of hypoglycemia or convulsion. We report the case of an infant with familial glucocorticoid deficiency who presented with hyperpigmentation, gigantism, and motor developmental delay without documented hypoglycemia, convulsion, or circulatory collapse.

Case presentation: A 10-month-old Sri Lankan Sinhalese baby boy born to consanguineous parents presented with generalized hyperpigmentation and overgrowth since birth. He had marginal gross motor developmental delay. His weight, length, and head circumference were above normal range for his age. Investigations revealed low serum cortisol and high adrenocorticotrophic hormone levels with no cortisol response following adrenocorticotropin stimulation. Serum electrolytes and aldosterone levels were normal. A diagnosis of familial glucocorticoid deficiency was made based on isolated glucocorticoid deficiency, hyperpigmentation, and tall stature.

Conclusions: This case report highlights that glucocorticoid deficiency can present without documented hypoglycemia and circulatory collapse and a high degree of suspicion is needed in diagnosis.
\end{abstract}

Keywords: Adrenal disorders, Pediatric endocrinology, Pediatric neurology

\section{Background}

Familial glucocorticoid deficiency (FGD) is a rare autosomal recessive disorder characterized by isolated glucocorticoid deficiency with normal mineralocorticoid activity [1]. Two main types are described: type 1 , which is caused by mutations in the gene encoding for adrenocorticotrophic hormone (ACTH) receptor (melanocortin-2 receptor, $M C 2 R$ ); and type 2, due to a mutation in melanocortin-2 receptor associated protein $(M R A P)[2,3]$. Most of the reported cases of patients with FGD were diagnosed following episodes of hypoglycemia, recurrent convulsions, or circulatory collapse. Here, we report the case of an infant with

\footnotetext{
* Correspondence: sachithmetta@yahoo.com

${ }^{1}$ Colombo North Teaching Hospital, Ragama 11010, Sri Lanka

${ }^{2}$ Department of Paediatrics, Faculty of Medicine, University of Kelaniya,

Thalagolla Raod, Ragama 11010, Sri Lanka
}

FGD who presented with hyperpigmentation, gigantism, and isolated gross motor developmental delay.

\section{Case presentation}

A 10-month-old Sri Lankan Sinhalese baby boy presented with generalized hyperpigmentation and overgrowth since birth (Fig. 1). He was born at term following an uncomplicated antenatal period and had a normal perinatal period without episodes of hypoglycemia or circulatory collapse. He was the only child of a pair of consanguineous parents. His growth parameters at birth were within normal limits; weight $3.3 \mathrm{~kg}$ (at median for age), length $50 \mathrm{~cm}$ (at median for age), and head circumference $35 \mathrm{~cm}$ (between median and $+1 \mathrm{SD}$ ). Since birth his growth chart demonstrated accelerated growth in weight, length, and head circumference (Fig. 2). His parents observed hyperpigmentation

(c) The Author(s). 2019 Open Access This article is distributed under the terms of the Creative Commons Attribution 4.0 International License (http://creativecommons.org/licenses/by/4.0/), which permits unrestricted use, distribution, and 


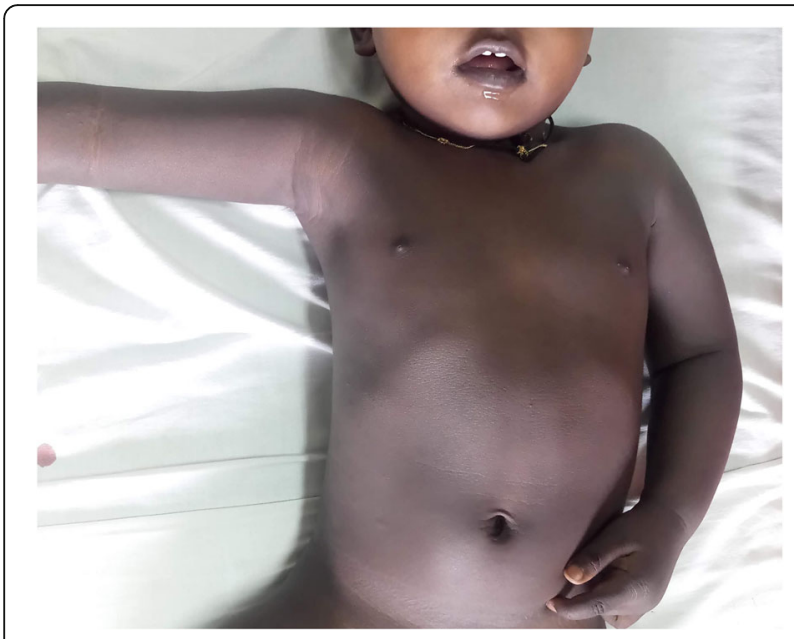

Fig. 1 Photograph of the child demonstrating marked hyperpigmentation

at birth which worsened gradually over time. His developmental history revealed marginal gross motor developmental delay; at 10 months of age, he was able to sit without support, however, he was unable to come to seated position on his own, stand with support, or crawl. His vision, fine motor, speech, and social development milestones were age appropriate. There were no previous hospital admissions, recurrent infections, seizures, episodes of shock, or documented hypoglycemia.

On examination, his length was $84 \mathrm{~cm}$ (above $+3 \mathrm{SD}$ ), weight was $12.6 \mathrm{~kg}$ (at $+3 \mathrm{SD}$ ), and head circumference was $48 \mathrm{~cm}$ (at $+2 \mathrm{SD})$. He had generalized hyperpigmentation involving oral mucosa, palms, and soles. The rest of the physical examination, including cardiovascular system, blood pressure, abdomen, and genitalia was clinically normal.

Basic hematological and biochemical investigations that included full blood count, C-reactive protein, renal and liver function tests, and serum electrolytes were normal. His random blood glucose was $76 \mathrm{mg} / \mathrm{dl}$. Subsequent investigations revealed very low serum cortisol $(<22 \mathrm{nmol} / \mathrm{l}$; normal $55-304 \mathrm{nmol} / \mathrm{l})$ and very high ACTH $(>1734 \mathrm{pg} / \mathrm{ml}$; normal $10-50 \mathrm{pg} / \mathrm{ml})$ suggesting glucocorticoid deficiency. His serum aldosterone level was normal. An ACTH stimulation test demonstrated markedly reduced basal cortisol levels $(<4.39 \mathrm{nmol} / \mathrm{L})$ with no cortisol response following administration of synthetic ACTH (cortisol remained $<4.39 \mathrm{nmol} / \mathrm{L}, 30$ and 60 minutes after ACTH stimulation) suggesting severe glucocorticoid deficiency. MRI of his brain showed normal pituitary gland with marginal dilatation of the trigone and the body of the lateral ventricles; however, there was no hydrocephalus or structural brain abnormalities.
FGD was diagnosed based on isolated glucocorticoid deficiency, hyperpigmentation, and tall stature. Molecular testing was not done due to unavailability. The baby was started on orally administered hydrocortisone $10 \mathrm{mg} / \mathrm{m}^{2}$ per day and his parents were counseled on the requirement for lifelong steroids. A review of this baby 5 months after initiating treatment revealed less pigmentation and slowing of growth in weight, length, and head circumference (Fig. 2) confirming the diagnosis.

\section{Discussion and conclusions}

FGD is a rare disorder which is characterized by isolated glucocorticoid deficiency and tall stature presenting in the first decade of life $[3,4]$. In most of the previous reports, patients presented with recurrent episodes of hypoglycemia with or without repeated convulsions. However, our patient did not have episodes of symptomatic hypoglycemia. Diagnosis of this child was based on hyperpigmentation and tall stature which led us to investigate for possible adrenal insufficiency.

Tall stature in FGD has been attributed to extremely high levels of ACTH acting through other melanocortin receptors, that is, melanocortin-1 receptor (MC1R) to melanocortin-5 receptor (MC5R), to affect bone and cartilage growth independent of growth hormone activity [3]. Five members of the melanocortin receptor family (MC1R to MC5R) are expressed in varying degrees in bone and high levels of ACTH acting on these receptors give rise to tall stature [5]. So far, to the best of our knowledge, all patients described in the medical literature have had tall stature which has not been associated with increased weight gain. In contrast, our patient had symmetrical overgrowth in all growth parameters including weight, height, and head circumference. Although FGD is not directly linked to increased weight gain, mutations in the related accessory protein melanocortin receptor accessory protein 2 (MRAP2), which is predominantly expressed in the hypothalamus, is associated with mammalian obesity [6]. It may be possible that weight gain in our patient is mediated through this protein. Excessive head growth is possibly mediated through the action of ACTH on bone growth through melanocortin receptors.

Another unusual finding of this case report is the isolated gross motor developmental delay. Although this is not previously reported in association with FGD, marginal isolated gross motor delay might have resulted from episodes of asymptomatic hypoglycemia which were not documented during the neonatal period. Also, excessive body weight could have contributed to marginal delay in gross motor milestones.

In conclusion, this case report highlights that glucocorticoid deficiency can present without documented hypoglycemia and circulatory collapse; therefore, 


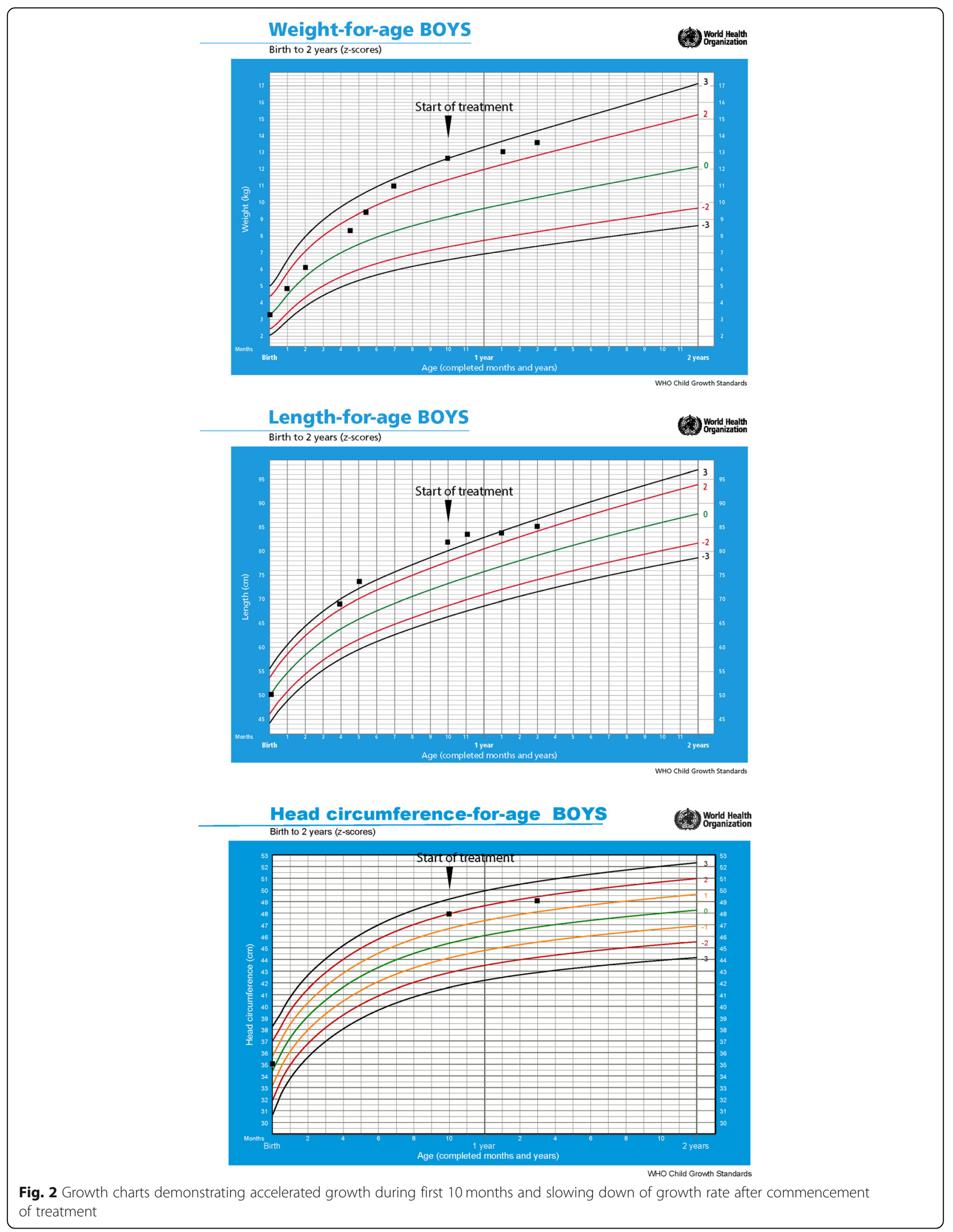


a high degree of suspicion is needed in diagnosis. FGD should be suspected in children who present with hyperpigmentation with overgrowth and must be appropriately referred for early diagnosis and treatment to minimize long-term complications.

\section{Abbreviations}

ACTH: Adrenocorticotrophic hormone; FGD: Familial glucocorticoid deficiency; MC1R: Melanocortin-1 receptor; MC2R: Melanocortin-2 receptor; MC5R: Melanocortin-5 receptor; MRAP: Melanocortin-2 receptor associated protein; MRAP2: Melanocortin receptor accessory protein 2

\section{Authors' contributions}

All authors contributed to the clinical management of patient, writing of manuscript, and final approval of the manuscript.

\section{Funding}

Not applicable.

\section{Availability of data and materials}

Not applicable.

\section{Ethics approval and consent to participate}

Not applicable.

\section{Consent for publication}

Written informed consent was obtained from the patient's legal guardian(s) for publication of this case report. A copy of the written consent is available for review by the Editor-in-Chief of this journal.

\section{Competing interests}

The authors declare that they have no competing interests.

Received: 1 February 2019 Accepted: 26 July 2019

Published online: 04 September 2019

\section{References}

1. Shivaprasad KS, Dutta D, Jain R, Ghosh S, Mukhopadhyay S, Chowdhury S. Familial glucocorticoid deficiency presenting with generalized hyperpigmentation in adolescence. Report of three siblings. Indian J Endocrinol Metab. 2012;16(Suppl 2):S382-4.

2. Meimaridou E, Hughes CR, Kowalczyk J, Guasti L, Chapple JP, King PJ, et al. Familial glucocorticoid deficiency: New genes and mechanisms. Mol Cell Endocrinol. 2013;371(1-2):195-200.

3. Elias LL, Huebner A, Metherell LA, Canas A, Warne GL, Bitti ML, et al. Tall stature in familial glucocorticoid deficiency. Clin Endocrinol. 2000;53(4):423-30.

4. Chung TT, Chan LF, Metherell LA, Clark AJ. Phenotypic characteristics of familial glucocorticoid deficiency (FGD) type 1 and 2. Clin Endocrinol. 2010; 72(5):589-94.

5. Zhong Q, Sridhar S, Ruan L, Ding KH, Xie D, Insogna K, et al. Multiple melanocortin receptors are expressed in bone cells. Bone. 2005;36(5):820-31.

6. Jackson DS, Ramachandrappa S, Clark AJ, Chan LF. Melanocortin receptor accessory proteins in adrenal disease and obesity. Front Neurosci. 2015;9:213.

\section{Publisher's Note}

Springer Nature remains neutral with regard to jurisdictional claims in published maps and institutional affiliations. 